\title{
A stealing syndrome after an iliaco-mesenteric bypass graft
}

\author{
Artur Witalis ${ }^{1}$, Maciej Pytka ${ }^{1,2,3}$, Grzegorz Halena ${ }^{2}$ \\ ${ }^{1}$ Department of Vascular Surgery, Voivodship Specialistic Hospital in Slupsk, Poland \\ ${ }^{2}$ Clinic of Cardiac and Vascular Surgery, Medical University of Gdansk, Poland \\ ${ }^{3}$ Department of Health Sciences, Pomeranian Academy in Slupsk, Poland
}

\begin{abstract}
A 68-year-old-woman reluctant to eat solids and liquid food with a history of post-eating abdominal pains - full-blown symptoms of abdominal angina, weakness, easily fatigued during exercise, and periodic diarrhea was referred to the documented hospital in order to perform elective iliacomesenteric by-pass.

Physical examination revealed a body mass index $15 \mathrm{~kg} / \mathrm{m}^{2}$, weight loss was more than $10 \%$ during the 6 months prior to presenting, abdomen soft, painless on palpation without pathological resistance. Outpatient gastro- and colonoscopy revealed no pathological changes. The computed tomography angiography scan of visceral and lower limb arteries revealed critical stenosis of the celiac trunk (length $10 \mathrm{~mm}$ ), $90 \%$ stenosis of the superior mesenteric artery over a length of $20 \mathrm{~mm}$ (Fig. 1A) and bilateral iliac artery stenosis of $80 \%$ was without any clinical manifestation (Fig. 1B). The patient was qualified for classical iliaco-mesenteric by-pass grafting. Immediately after surgery, in the recovery room, the patient suffered symptoms of acute left limb ischemia in the form of pallor, bruises, vein collapse, and severe pain. The patient
\end{abstract}

was transported to the catheterization laboratory where the angiography documented stealing syndrome caused by the vascular bridge (Fig. 1C). Subsequently, the percutaneous transluminal angioplasty of the left iliac axis was performed with implantation of two stents (Fig. 1D, E). After the endovascular procedure, symptoms of stealing syndrome subsided. The limb was correctly warmed, veins were properly filled and active movements and feeling were properly preserved. During discharge the patient showed no symptoms of abdominal angina, no post eating pain and without evidence of limb ischemia and a maximum walking distance of about $200 \mathrm{~m}$. At 4 weeks the patient gained about $4 \mathrm{~kg}$ and remained asymptomatic.

Herein is presented a unique case of acute limb ischemia due to stealing syndrome after iliacomesenteric graft surgery subsequently treated using the percutaneous transluminal angioplasty procedure.

Most cases describe stealing syndrome and intestinal ischemia due to blood stealing from bypass graft to ischemic limb.

Conflict of interest: None declared

Address for correspondence: Dr. Maciej Pytka, Department of Vascular Surgery, Voivodship Specialistic Hospital in Slupsk, ul. Hubalczyków 1, 76-200 Słupsk, Poland, e-mail: pytka.maciej@gmail.com

Received: 09.09.2017 Accepted: 17.01.2018 


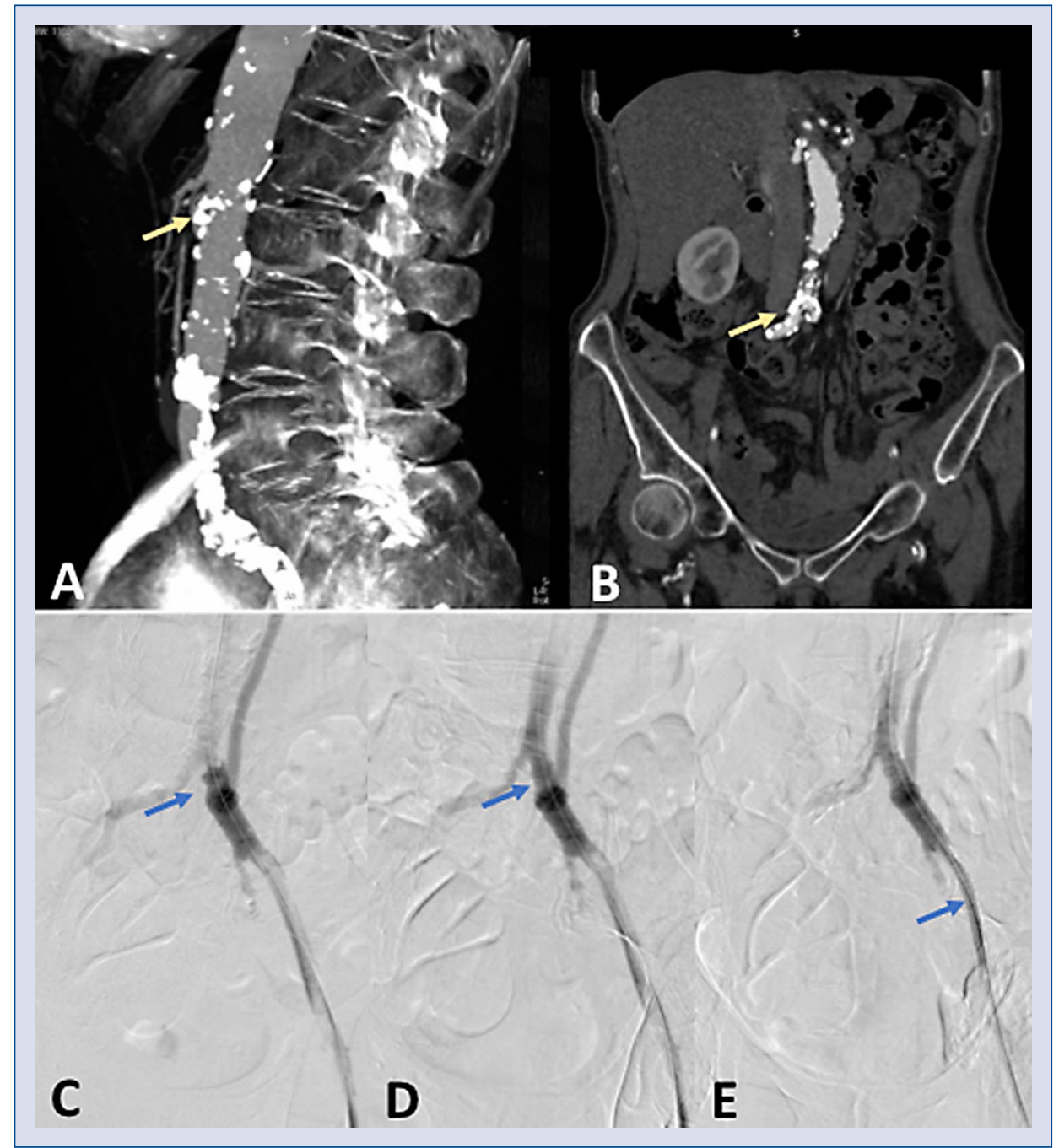

Figure 1. A-E. Atherosclerotical lesions in superior mesenteric artery and iliac arteries, angioplasty and stent implantation in left iliac axis. 